\title{
The Analysis of the Role of Information Technology (IT) in making the Knowledge of the Knowledge-Based High-Tech Companies Explicit (The Case Study: Companies of Pardis Science and Technology Park)
}

\author{
Ahmad Jafarnejad \\ Professor of Faculty of Management, Tehran University, Tehran, Iran
}

Seyyed Abolghasem Mira

Assistant Professor of Faculty of Management, Tehran University, Tehran, Iran

\author{
Sonia Habibi Rad \\ (Corresponding Author)
}

MSc. Student in MBA, Faculty of Management, Tehran University, Tehran, Iran

E-mail: Soniahabibirad@yahoo.com

\author{
Accepted: Sep 13, 2013 Published: October 01, 2013 \\ Doi:10.5296/ijld.v3i5.4364ＵRL: http://dx.doi.org/10.5296/ijld.v3i5.4364
}

\begin{abstract}
In the resource-based theory, the balance between knowledge and other resources is for the benefit of the changed knowledge, so that knowledge has become a determinant factor, even more than land, work and capital. But the development of the organizational knowledge is rooted in organizational learning that appears at all of organizational levels and the most important way for improving the level of the organizational learning is also the management of the tacit knowledge of the employees and turning it into the explicit knowledge. On the other hand, information technology (IT) has opened a new area for releasing, interchanging and presenting information by the human that is considered a deep revolution in many aspects. The main purpose of the research is to analyze the role of information technology in making the knowledge of the companies with a high technology of the science and technology park explicit, and the population of the research is the managers and the experts of the companies of Pardis science and technology park in Tehran. Using the sampling formula and substituting the standard deviation taken from the distribution of the elementary questionnaire in it, the sample size was obtained 142 and after distributing the standard questionnaire of the research, 154 complete questionnaires gathered from the employees and the managers of the companies of Pardis science and technology park were analyzed. After examining any of the variables of the research in the companies being examined through student t's test, variance analysis and LSD, although no significant relationship was observed between using IT and making knowledge explicit, the results indicated that there was a significant relationship between using IT in the external structure dimension and making knowledge explicit and most of the measures of this dimension were related to IT's infrastructures.
\end{abstract}

Keywords: Information Technology (IT), knowledge management, making knowledge explicit, science and Technology Park

\section{Introduction}

Today, the human has left the industrial civilization and has stepped into the infra-industrial stage, i.e. information civilization and enjoying knowledge (Yang et al., 2012). In the current world of competition, managers have found that knowledge and learning are a better resource 
for achieving a stable competitive advantage. They know that keeping the key knowledge of the organization passive in the minds of the employees is not good and factors such as replacement, the decline in the educational standards and the rapid growth of the business changes show that the vision and the pervasive and stable information of people can be no longer relied individually. So the knowledge enclosed in the employees must penetrate into the inside of the organization, so that everyone can access it and also increase or complement it. In other words, the tacit knowledge is turned into the explicit knowledge (Jafari et al., 2006).

In the societies and organizations that want to obtain the competitive advantage, management of knowledge is a useful tool for them to convert the tacit knowledge into the explicit knowledge and develop their intellectual capital and through it, to maximize the desirable performance (Vahedi\&Nejad Haji, 2011). Undoubtedly, the concept of knowledge management will have very limited capabilities without knowledge-based technologies. The highest value of technology in knowledge management is to increase the accessibility to knowledge and accelerate its transfer. IT makes it possible to draw the knowledge (the tacit knowledge) from the mind of the one having the knowledge. Then, using the technology, the knowledge can be reordered (making knowledge explicit) and transferred to every place in the world (Afrazeh, 2004). IT helps encode the knowledge, decode it and sometimes create it. Creating suitable infrastructures based on IT helps very much to the success of the knowledge management and is considered a suitable tool for making the tacit knowledge explicit (Tseng, 2008).

On the other hand, the absence of an integrated chain of research, technology, knowledge and development and the high distance between scientific and research ideas about the products and the services are the facts of the present world. To solve this challenge, the developed countries of the world consider the whole scientific, technological and industrial system of the society, ranging from creating idea to commercializing the finished product, as a whole system called the innovation system beside and interacting with each other. One of the elements of this system is the scientific and technological parks that play an important role in integrating knowledge production, making it explicit and representing it in products and services. In this system, the existence of the knowledge management approach plays an important role in connecting knowledge to technology. Parks have advantages close to those of the important resources of the immaterial capital, suitable infrastructures and the directing policies and facilitate technology-based partnerships and economic growth (Kharghani\&Selseleh, 2008). The emergence of the science and technology parks is for identifying and using the knowledge creating the competitive advantage for the organizations according to the evolution era and environmental non-confidences. Establishing the knowledge management approach and making knowledge explicit using IT tools can play an important role in the success of these parks (Salari et al., 2011). In fact, the emergence of the science and technology parks in the developed countries is for settling the theoretical and practical tensions and the emergence of knowledge and science and technology, i.e. the products and services (Keramati et al., 2008), while in most of the developing countries, these loops exist as separated islands separated. Knowledge is created without thinking about its application and knowledge creators don't find a field to use their research achievements. The cycle of knowledge management at the microlevel is to find the knowledge existing in the organization that is created before (cycle of knowledge creation), reorder it (organizing loop), interchange it (involving knowledge interested people) and use it (reflecting knowledge and displaying it as a product or a service). At the macro-level, using the knowledge management approach, the separated loops of creating, organizing, interchanging and using knowledge can be integrated as the products and services (making knowledge explicit). The success of the science and technology parks that play an important role in the scientific-economic growth and development in many countries has made this pattern be reproduced quickly in various countries. In fact, the economic 
development of many developed and developing countries is due to the existence of science and technology parks. Because of the successful performance of the firms active in science and technology parks, the appearance of the regions where these parks act has been perfectly altered and they have been changed from resting and inactive regions to the most moving and advanced industrial centers of the world (Kharghani\& Selseleh, 2008). But such economic firms have been always unaware of the necessity of using modern technologies to promote their knowledge. With this introduction and according to the necessity of using knowledge management and IT for the success of science and technology parks, in this research, we want to examine the role of IT in making knowledge of the companies existing in the science and technology parks explicit and present a new and efficient way for using the knowledge of the knowledge-based organizations properly. On the other hand, IT measures will be rated in terms of the level of their effects on making knowledge explicit using multi-measures decision making techniques.

\section{The review of the history of the research}

In the literature of knowledge management and organizational knowledge, IT is introduced as a central issue. In the recent 3 to 5 years, some researchers have noticed the relationship between knowledge management and IT and have estimated that almost $70 \%$ of the literatures on the subject of knowledge management are focused on designing IT. In its theoretical form, knowledge management is a multidisciplinary subject, but in practice, it emerges in the subject of IT in many organizations that manages IT's task and takes on the information. Although knowledge is not exclusively the product of IT, IT has constantly involved in knowledge creation and the process of knowledge management from the first years. Today, knowledge management is taken mainly as one of the responsibilities of IT, because information and knowledge play the key role in collecting, converting and transferring data. In practice, knowledge management is a mixture of business leadership and culture and technology. These aspects are elegantly related to each other. Neither the technology nor a merely commercial-cultural procedure can present an effective program of knowledge management alone (Gogan, 2006).

For a long time, the role of IT in sharing knowledge was the core subject of discussion. Many researchers insist that the rules of knowledge management can perform successfully without using IT tools. Another group believe that IT is strategically necessary for the global range and domain where organizations are geographically distributed (Kane\&Alavi,2007; Argote et al., 2003; Zack, 2005).

Salari et al. (2011) has determined and prioritized factors effective in the success of knowledge management in the science and technology parks. The population of this research was 9 centers of science and technology parks located in Yazd, Iran. Researchers have classified the effective factors in 31 minor factors as 7 major factors including human force, guideline, management, evaluation, organizational culture, processes and IT. Based on studying the history of the research and with the help of the hierarchical analysis process and using the ideas of the experts and the professionals, the researchers have weighted these factors. According to the results obtained, the prioritization of the major factors effective in knowledge management is as follows:

1. Human resource, 2. Guideline, 3. Management, 4. Organizational culture, 5. Processes, 6. Evaluation and 7. IT

As a factor effective in the success of knowledge management, measures of IT are as follows:

- The IT capability of the units

- The budget assigned for establishing IT infrastructures

- $\quad$ The existing IT infrastructures

- The capability of using management information system 
- The existence of IT human resources

- Using Internet and intranet

Abasi and Maki (2010) examined the necessity of innovation in implementing the programs of knowledge management and IT management in Iran. In this research, the researchers discussed the basic hypotheses of knowledge management and its relation with IT theoretically and practically. After examining the trend of the formation of knowledge management, they stated that despite the close relation between IT and knowledge management, technology can't be replaced by human. Finally, after examining the rules and the barriers of knowledge management, they presented the following innovative solutions for applying the programs of knowledge management with the help of IT:

- Developing information and communicational infrastructures such as satellites, optical fibers, internet and mass media

- Justifying and training managers and employees

- making regulations specific to the knowledge-based societies

- The necessity of creating a practical attitude to the effect of IT on knowledge management

In a study, Madadi et al. (2010) examined the role of IT in the effectiveness of the knowledge-based organizations. The researchers obtained their required data by distributing questionnaires among the faculty members of the collage of the agriculture and natural resources, Tehran University. After analyzing the data, it was concluded that using information in the areas such as meeting scientific and professional needs of the scholars, improving the career performance, increasing job satisfaction, supporting managers' decisions, and making the knowledge of the faculty members explicit is very necessary.

Shahvali and Lachini (2007) examined the management of the tacit knowledge of the food security of the Agricultural Jihad, Fars Province. In their research, they used Robertson's model (2004), in which the approaches existing in the knowledge management were classified into two classes of "top-down" and "bottom-up" approaches (Robertson, 2004). Using this model, the key groups of the research were the experts and the managers of the Agricultural Jihad, Fars Province. The results showed that $80 \%$ of people with tacit knowledge about the food security obtained a score lower than 20 from 50. Also, findings of the study showed that the highest consumption of the resources of the explicit knowledge included books, magazines, reports, and organizational researches, respectively. Also, most of the communicational methods used for promoting the tacit knowledge were talking with the colleagues, participating in seminars and face-to-facer conversations. Using magazines and talking with the colleagues have a positive significant correlation with the tacit knowledge of the food security of people.

In an article, Farhoudi and Doroudi (2008) examined the role of making knowledge explicit and its management in improving the quality of the library services. According to them, factors and infrastructures of knowledge must be provided to make it explicit and manage it and the most important factors and infrastructures are communication technology and information.

They have examined the facilities that information and communication technology provide and can provide the base and the infrastructure for making knowledge explicit. Some of these facilities include internet, intranet, groupware, artificial intelligence, and many specialized software.

In his article, Afrazeh (2004) introduces knowledge management and its elements (explicit-tacit). Then, he examines Nonaka-Takeuchi's (1994) model that proposes the way and the process of converting these two types of knowledge to each other and discusses the role and the way of using technology in these processes. 


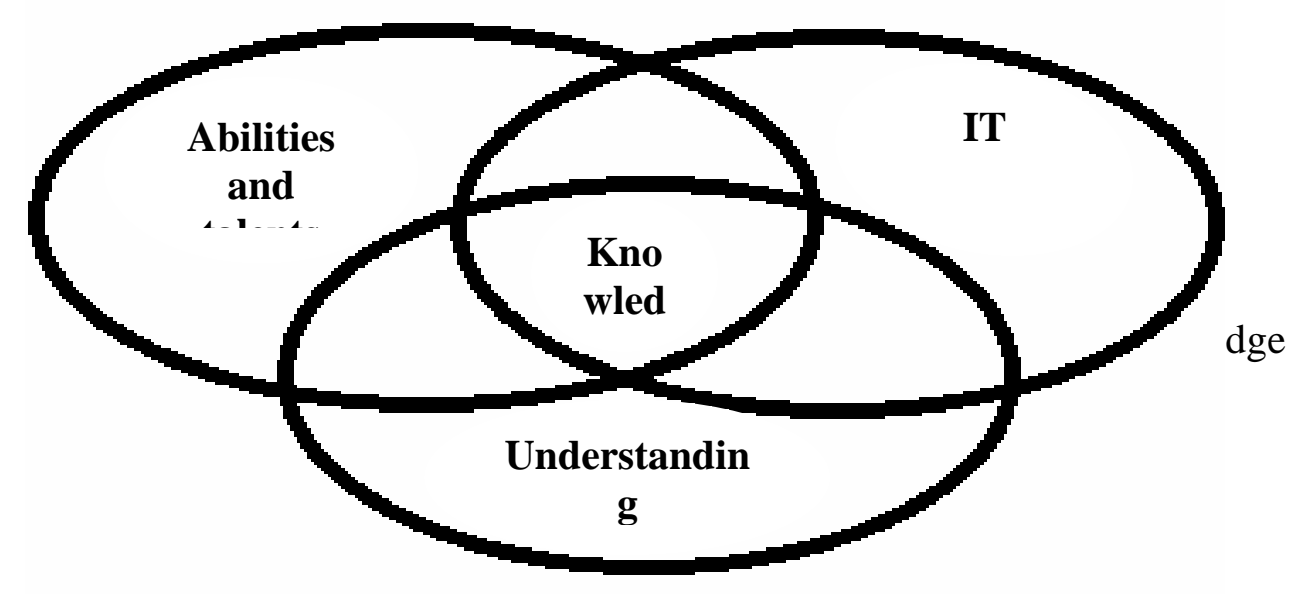

\section{Tacit to explicit}

Answering the questions

Interpretation

\section{Explicit to explicit}

Text searching

Classifying the documents

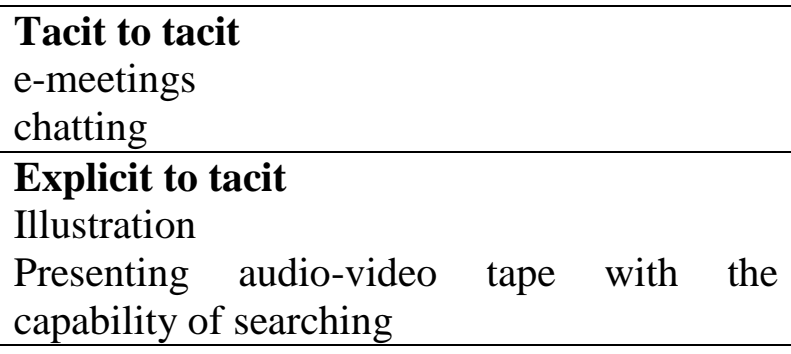

Figure 2. Examples from ITs that can enhance or support transferring and making knowledge explicit (source: Afrazeh, 2004)

In an article, knowledge management in intellectual organizations including universities, research centers, science and technology parks, etc, Ahmadi (2004) has stated that processes such as creativity, innovation, problem solving, doing research, learning and giving ideas are common subjects in the knowledge management of these organizations due to their research nature. He has given suggestions for creating knowledge and making it explicit in the intellectual organizations as follows:

- Creating the proper basis and culturalization for extending the knowledge capital and paying attention to it and managing, creating and extending IT for making knowledge management possible

- Identifying and revising knowledge management continuously

- Paying attention to the concepts and the values of the continuous learning through management of the intellectual capitals

In their article, Kharghani and Selseleh (2008) examined the types of the science and technology parks according to their nature and their purpose and stated the benefits from establishing knowledge management in the science and technology parks. Different science and technology parks are as follows:

Scientific parks, technological scientific parks, techno-polices, technological parks, science and industrial technology parks, research scientific towns, centers for the growth of the entrepreneurs, centers for business innovation, centers for technology services

According to the researchers, establishing knowledge management in different science and technology parks can: 
- Share the knowledge of the experts

- Convert intellectual or knowledge-based properties to the wealth

- Discover knowledge properties and design ways for benefitting from these properties (making knowledge explicit)

- Manage intellectual capitals properly

- Promote basic competencies

- Draw knowledge map and identify people with a special knowledge

- Manage information systems properly

- Prevent from a drop in the knowledge

- Improve the relation between university and industry

Yang et al. (2012) has examined the effect of information technology on the success of the project through knowledge management. His research hypotheses were as follows:

1) IT affects on the level of the knowledge management of the project.

2) IT affects positively on the performance of the project.

3) Knowledge management affects positively on the performance of the project.

4) Project management affects positively on the profit of the project.

5) The relation between IT and project management is affected by knowledge management.

The results from reviewing the questionnaires distributed in Taiwan's construction schemes showed that IT tools widely affect on the knowledge management. Using IT tools is dependent on the level of knowledge management and according to the atmosphere governing the knowledge management of the projects being examined, the researchers have suggested using e-mail, document management system, Autocad, search engines, using data and text browsing techniques as the technologies for improving the knowledge management of a project.

The researchers have also found that using IT reduces costs and improves the quality and reduces the period of the project. Examining IT and knowledge management, Vahedi\&NejadHaji (2001) stated that the best way of using IT for knowledge management is the combination of two factors:

1. Being aware of the limitations of IT and the fact that as long as ITs don't fit the organizational and the global culture, they are not useful.

2. The accessibility of ITs clearly designed for knowledge management.

The question that the researchers proposed in their research is that:

In their review, Mohamed et al. (2006) described new views about the role of IT in knowledge management. In his article, he proposed the weaknesses and the strengths of applying IT to knowledge management. According to the author, the bivalent logic of IT must be broken and the learning must occur in a true spectrum, until IT is effective for knowledge management. He believes that the key to achieve a consistency between IT and knowledge management is to know the following rules:

- There are cases which the technology does better, there are also cases which the human does better.

- Most of the tensions between knowledge management and IT are to use them in other fields.

- Instead of integrating IT with knowledge management, there must be a bridge between them and IT must be used in all stages of knowledge management properly.

In a review of several big American and Taiwanese companies and organization, Huang et al. (2006) concluded that in knowledge-based organization, due to the high volume of knowledge and information on stream, IT facilitates obtaining, storing and converting the tacit knowledge to the explicit knowledge as one of the key tools of knowledge management. Hence, in these organizations, IT management is observed more than other organizations by the researchers. He suggests that information must be accessed any time to be converted into a 
knowledge-based organization, because making knowledge updated is one of the main qualities of the knowledge-based organizations. Researchers believe that except the moral and security issues, imposing any constraint on the information access delays the creation of a knowledge-based organization.

For this purpose, examining several knowledge-based organizations and comparing them with the traditional organizations, Chinho\&Mei (2005) concluded that in the knowledge-based organizations, IT is used divergently, dynamic and widely, and these organizations use it for transferring the tacit knowledge and making it explicit, compared to the traditional organizations that use IT narrowly and statically.

In another research, in addition to addressing the importance and the necessity of the existence of IT in the knowledge-based organizations and the success of the knowledge management as a key factor, Oppong (2005) stated that for the knowledge management to be effective in the success of a business, especially in the electronic commerce, innovation and creativity must be also used beside IT. This is shown in the following figure. Also, according to the researcher, while investing in IT, knowledge-based organizations must attach equal importance to the tacit and explicit knowledge and make them balanced.

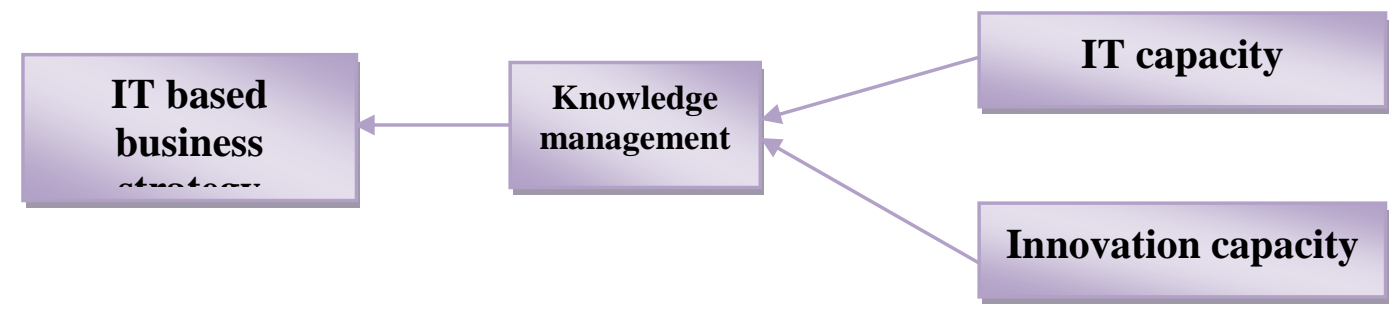

Figure 3. the organizational capacities required for the success of knowledge management (source: Oppong,2005)

As it is seen, many studies have analyzed the role of IT in the knowledge management, but the innovation of the present research is that for the first time, the role of IT is examined in any of the aspects of making knowledge explicit as the famous Nonaka's model, in order that the practical results are presented to the heads of the knowledge-based organizations of the science and technology parks.

\section{Method Of The Research}

The method employed in this research is an analytical-survey one. A mixture of library and field methods of research is used for data collection. The library method is mainly used for studying the literature of the subject and examining the history of the research and being familiar with the applications of IT, organizational intelligence, and knowledge management models, especially in the knowledge-based companies. In this stage, according to the history of the research, measures related to IT are extracted and doing a survey of the managers and the experts of Pardis science and technology parks and using the present circumstance questionnaire, the present level of IT is determined in these organizations. On the other hand, the existence of a significant difference in different aspects of IT is also determined using ANOVA test. In the second stage, the present level of any measures of making knowledge explicit is determined in the companies being examined and according to the scores obtained from the present circumstance, the correlation between any of the aspects of IT and making knowledge explicit is analyzed. In this research, the most important tool for data analysis is SPSS software that is used for testing the hypotheses. It is also used for determining the sample size and other correlation estimations. It must be mentioned that the correlation test must be used for finding a significant relation between two variables. For obtaining more accurate 
results, the questionnaires of the research are classified based on Likert's seven point spectra from very high to very low. On the other hand, IT measures are ranked in terms of the level of their effect on making knowledge explicit and using TOPSIS technique to achieve more accurate results.

As it is also evident from the title of the research, an independent variable (IT) and a dependent variable (making knowledge explicit) are studied in this research and for measuring any of these variables, a distinct questionnaire is used. The most comprehensive questionnaire in relation to the factors effective in the application of IT in small and medium sized organizations is developed by Alidousti (2010) that includes four basic internal and external dimensions. For this reason, five major hypotheses are examined in this research.

1. The application of IT significantly affects on making knowledge explicit in the science and technology park.

2. The process factors of the application of IT significantly affect on making knowledge explicit in the science and technology park.

3. The content factors of the application of IT significantly affect on making knowledge explicit in the science and technology park.

4. The internal structure factors of the application of IT significantly affect on making knowledge explicit in the science and technology park.

5. The external structure factors of the application of IT significantly affect on making knowledge explicit in the science and technology park.

It must be mentioned that in the present research, Nonaka's model (Nonaka\&Takeuchi, 1994) is used for measuring the status of making knowledge explicit that is referred in various articles. In one of the recent articles in this field, this model is divided into eight sections to conclude more accurately (Rafati Shaldehi et al., 2008) and its measures are the basis of the examination of making knowledge explicit in this research.

In this research, the limited population sampling method was used due to the high number of the employees and the managers of the companies of pardis science and technology parks. Since in this research, the size of the population being studied is about 950 people, an elementary sampling was used to determine the standard deviation of the population. For this purpose, the questionnaire of the research was randomly distributed among 43 managers and employees. The results from examining the standard deviation of the questions of the research showed that the highest standard deviation of the population is 0.329 . So according to the standard deviation obtained, the maximum sample size estimated at the level of error 5\% is 142 and after distributing the questionnaires, 154 complete questionnaires were finally used as the basis of the analyses.

$$
n=\frac{N \times Z_{\alpha / 2}^{2} \times \delta^{2}}{\varepsilon^{2}(N-1)+Z_{\alpha / 2}^{2} \times \delta^{2}} \Rightarrow n=\frac{950 \times(1.96)^{2} \times 0.329^{2}}{0.05^{2}(949)+(1.96)^{2} \times 0.329^{2}}=142
$$

\section{Results Of The Research}

After measuring and proving the validity and the reliability of the questionnaires of the research, the statistical tests were conducted as follows. In the following, the final results will be presented. Before doing any statistical analysis, it is necessary to make sure of the normality or non-normality of the data distribution. For this purpose, we must use Kolmogorov-Smirnov test. Based on the results of the following table and the significance level 0.121, the distribution of the data is normal in the questionnaire of the present circumstance of using IT and in the following, the parametric tests must be used for data analysis. 
Table1. Kolmogorov-Smirnov test for the questionnaire of the present circumstance of using IT

One-Sample Kolmogorov-Smirnov Test

\begin{tabular}{|c|c|c|}
\hline & & IT Data \\
\hline \multicolumn{2}{|l|}{$\mathrm{N}$} & 154 \\
\hline Normal Parameters ${ }^{\mathrm{a}}$ & Mean & 3.8569 \\
\hline \multirow{4}{*}{ Iost Extreme Differences } & Std. Deviation & .75919 \\
\hline & Absolute & .095 \\
\hline & Positive & .082 \\
\hline & Negative & -.095 \\
\hline \multicolumn{2}{|c|}{ Kolmogorov-Smirnov Z } & 1.184 \\
\hline \multicolumn{2}{|c|}{ Asymp. Sig. (2-tailed) } & .121 \\
\hline
\end{tabular}

a. Test distribution is Normal.

In this section, the results of the data analysis of any of the four dimensions of using IT are stated, i.e. the process, the content, the internal structure and the external structure dimensions. In the first section, the results from data analysis are examined using the one-way student t's test and based on the hypotheses made. Since the questionnaire is based on Likert's seven point spectra, based on the statistical books, we must take strictly the mean or the value being tested equal to 4.

The typical hypothesis: IT factors related to the process dimension are at the desirable circumstance in companies of Pardis science and technology park.

For testing this hypothesis, the statistical hypothesis is designed as follows.

The IT factors related to the process dimension are not at the desirable circumstance in the companies of Pardis science and technology park. $H_{0}: \mu \leq 4$

The IT factors related to the process dimension are at the desirable circumstance in the companies of Pardis science and technology park. $H_{1}: \mu>4$

The one-way student t's test was used for testing this hypothesis and its findings are presented in table 2.

Table 2. Findings from the hypotheses in the dimensions of using IT

\begin{tabular}{|c|c|c|c|c|c|c|}
\hline & \multicolumn{6}{|c|}{ Test value $=4$} \\
\hline & \multirow[t]{2}{*}{$\mathrm{T}$} & \multirow[t]{2}{*}{ Df } & \multirow[t]{2}{*}{ Sig.(2-tailed) } & \multirow[t]{2}{*}{$\begin{array}{l}\text { Mean } \\
\text { Difference }\end{array}$} & \multicolumn{2}{|c|}{$\begin{array}{l}95 \% \text { confidence } \\
\text { interval of the } \\
\text { difference }\end{array}$} \\
\hline & & & & & lower & upper \\
\hline $\begin{array}{l}\text { Process } \\
\text { factors }\end{array}$ & -3.137 & 153 & .002 & -.27597 & -.4497 & -.1022 \\
\hline $\begin{array}{l}\text { Content } \\
\text { factors }\end{array}$ & -2.127 & 153 & .035 & -.17922 & -.3456 & -.0128 \\
\hline $\begin{array}{l}\text { Internal } \\
\text { structure }\end{array}$ & .596 & 153 & .552 & .04638 & -1.075 & .2003 \\
\hline $\begin{array}{l}\text { External } \\
\text { structure }\end{array}$ & -2.600 & 153 & .010 & -.21299 & -.3748 & -.0511 \\
\hline
\end{tabular}

Examining the hypotheses of the research, it became clear that three sets of factors related to using IT in the companies of Pardis science and technology park are at the desirable circumstance and only the internal structure, i.e. the existence of a flexible decision making 
system in the company and the existence of a positive attitude toward IT in the company, is not at the desirable circumstance.

Now this question arises that whether the level of the effect of these four sets of factors is equal or not. For answering the question, the statistical method, variance analysis (ANOVA), was used. The hypotheses related to this test are as follows:

There is no significant difference between the levels of the effect of the four sets of factors related to using IT. $H_{0}: \mu_{1}=\mu_{2}=\mu_{3}=\mu_{4}$

There is a significant difference between the levels of the effect of the four sets of factors related to IT. $H_{1}: \mu_{1} \neq \mu_{2} \neq \mu_{3} \neq \mu_{4}$

The findings from the variance analysis test are presented in table 3.

Table3. findings from the variance analysis of the dimensions of the present circumstance of using IT

ANOVA

\begin{tabular}{|c|c|c|c|c|c|}
\cline { 2 - 6 } \multicolumn{1}{c|}{} & um of Squares & df & Mean Square & F & Sig. \\
\hline Between Groups & 9.107 & 3 & 3.036 & 2.856 & .036 \\
Within Groups & 650.580 & 612 & 1.063 & & \\
Total & 659.688 & 615 & & & \\
\hline
\end{tabular}

The results from the variance analysis show that at the confidence interval $95 \%$, there is a significant difference between the means and the variances of the factors related to using IT in the companies of Pardis science and technology park. It must be mentioned that similar steps must be also taken for the questionnaire of making knowledge explicit and its results are described as follows:

This time, the first step is also doing Kolmogorov Smirnov test and according to the results, the distribution of the data is normal and the parametric tests are used as the basis.

Table 4. Kolmogorov-Smirnov test for the questionnaire of making knowledge explicit

One-Sample Kolmogorov-Smirnov Test

\begin{tabular}{|c|c|c|}
\hline & & KM Data \\
\hline \multicolumn{2}{|l|}{$\mathrm{N}$} & 154 \\
\hline Normal Parameters ${ }^{\mathrm{a}}$ & Mean & 3.9675 \\
\hline \multirow{4}{*}{ ost Extreme Differences } & Std. Deviation & 1.05346 \\
\hline & Absolute & .080 \\
\hline & Positive & .043 \\
\hline & Negative & -.080 \\
\hline \multicolumn{2}{|c|}{ Kolmogorov-Smirnov Z } & .997 \\
\hline \multicolumn{2}{|c|}{ Asymp. Sig. (2-tailed) } & .273 \\
\hline
\end{tabular}

a. Test distribution is Normal.

We use student t's test to examine the circumstance of making knowledge explicit in the companies of Pardis science and technology park, and the outputs are summarized to prevent from very long results. An instance of the hypotheses being examined about any of the eight dimensions of making knowledge explicit is presented in the following and the results of all of the dimensions are also presented in table 5.

The typical hypothesis: the factors of making knowledge explicit related to the dimension of the individual tacit knowledge are at the desirable circumstance in the companies of science and technology park.

For testing this hypothesis, the statistical hypothesis is designed as follows. 
The factors of making knowledge explicit related to the dimension of the individual tacit knowledge are not at the desirable circumstance in the companies of Pardis science and technology park. $H_{0}: \mu \leq 4$

The factors of making knowledge explicit related to the dimension of the individual tacit knowledge are at the desirable circumstance in the companies of Pardis science and technology park. $H_{1}: \mu>4$

Table 5. student t's test for all of the dimensions of the questionnaire of making knowledge explicit

\begin{tabular}{|c|c|c|c|c|c|c|}
\hline \multirow[t]{3}{*}{ Dimensions } & \multicolumn{6}{|c|}{ Test value $=4$} \\
\hline & \multirow[t]{2}{*}{$\mathrm{T}$} & \multirow[t]{2}{*}{ df } & \multirow[t]{2}{*}{ Sig.(2-tailed) } & \multirow[t]{2}{*}{$\begin{array}{l}\text { Mean } \\
\text { Difference }\end{array}$} & \multicolumn{2}{|c|}{$\begin{array}{l}95 \% \text { confidence } \\
\text { interval of the } \\
\text { difference }\end{array}$} \\
\hline & & & & & Lower & upper \\
\hline $\begin{array}{l}\text { Individual } \\
\text { tacit } \\
\text { knowledge }\end{array}$ & -2.347 & 153 & .020 & -.21158 & -.3896 & -.0335 \\
\hline $\begin{array}{l}\text { Making } \\
\text { explicit }\end{array}$ & -2.017 & 153 & .045 & -.18669 & -.3696 & -.0038 \\
\hline $\begin{array}{l}\text { Individual } \\
\text { explicit } \\
\text { knowledge }\end{array}$ & -.141 & 153 & .888 & .01391 & -.2087 & .1809 \\
\hline Conversion & -.472 & 153 & .638 & -.04257 & -.2209 & -.1357 \\
\hline $\begin{array}{l}\text { Collective } \\
\text { explicit } \\
\text { knowledge }\end{array}$ & -1.601 & 153 & .112 & -1.6667 & -.3724 & .0391 \\
\hline Internalization & 2.443 & 153 & .016 & .25974 & .0497 & .4697 \\
\hline $\begin{array}{l}\text { Collective } \\
\text { tacit } \\
\text { knowledge }\end{array}$ & 2.248 & 153 & .026 & .23377 & .0284 & .4392 \\
\hline Socialization & 1.274 & 153 & .204 & .14935 & -.0822 & .3809 \\
\hline
\end{tabular}

In the table above, dimensions with a significance level lower than 0.05 are at the desirable circumstance and four dimensions are in this group. On the other hand, looking at the table of the mean and the standard deviation, it is clear that the last three dimensions that show the individual and collective tacit knowledge have a higher mean than other dimensions and the companies of Pardis science and technology park are in a stage between the internalization and the socialization in terms of the levels of making knowledge explicit. In the following, ANOVA test is conducted to determine the existence of a difference between groups. The hypothesis of this test is as follows.

There is no significant difference between the levels of the effect of the eight dimensions of making knowledge explicit.

$H_{0}: \mu_{1}=\mu_{2}=\mu_{3}=\mu_{4}=\mu_{5}=\mu_{6}=\mu_{7}=\mu_{8}$

There is a significant difference between the levels of the effect of the eight dimensions of making knowledge explicit.

$H_{1}: \mu_{1} \neq \mu_{2} \neq \mu_{3} \neq \mu_{4} \neq \mu_{5} \neq \mu_{6} \neq \mu_{7} \neq \mu_{8}$ 
Table 6. Findings from the variance analysis of the dimensions of the questionnaire of making knowledge explicit

\begin{tabular}{|c|c|c|c|c|c|}
\multicolumn{1}{c|}{} & ANOVA \\
\cline { 2 - 6 } \multicolumn{1}{c|}{} & um of Squares & Df & Mean Square & F & Sig. \\
\hline Between Groups & 39.079 & 7 & 5.583 & 3.570 & .001 \\
Within Groups & 1914.245 & 1224 & 1.564 & & \\
Total & 1953.325 & 1231 & & & \\
\hline
\end{tabular}

The results from the variance analysis show that at the confidence interval 95\%, there is a significant difference between the means and the variances of the dimensions of making knowledge explicit in the companies of Pardis science and technology park.

The third questionnaire of the research is distributed for prioritizing the importance of IT measures in making the knowledge of the companies of Pardis science and technology park explicit. The following table shows the ranks of the measures rated based on TOPSIS technique and as it is clear, measures including the suitable price of the required software, the positive attitude of the senior manager of the company to IT and the integration of IT with the marketing practice of the company have the highest effect on making the knowledge of the employees explicit.

Since the data distribution was normal in both questionnaires, the parametric correlation coefficients must be used for examining their relation and in this research, Pearson correlation coefficient is used and for making the results more accurate, Kendall test is also analyzed. In the first section, the results of the test of the correlation between using IT and making knowledge explicit are generally presented and in the next section, they are presented separately for any of the dimensions of using IT.

Table7. Prioritization of the importance of the measures using TOPSIS technique

\begin{tabular}{|l|l|l|l|l|}
\hline Measure & $\begin{array}{l}\text { Measure } \\
\text { no. }\end{array}$ & $\begin{array}{l}\text { Degree } \\
\text { importance }\end{array}$ & d+ & $\mathbf{d}-$ \\
\hline The suitable price of the required software & $\mathrm{A} 21$ & 0.544 & 0.01 & 0.012 \\
\hline $\begin{array}{l}\text { the positive attitude of the senior manager of } \\
\text { the company to IT }\end{array}$ & $\mathrm{A} 16$ & 0.541 & 0.01 & 0.012 \\
\hline $\begin{array}{l}\text { the integration of IT with the marketing } \\
\text { practice of the company }\end{array}$ & $\mathrm{A} 11$ & 0.525 & 0.01 & 0.011 \\
\hline $\begin{array}{l}\text { The existence of positive attitude to the IT } \\
\text { in the company }\end{array}$ & $\mathrm{A} 13$ & 0.521 & 0.01 & 0.011 \\
\hline $\begin{array}{l}\text { The existence of a flexible decision making } \\
\text { system in the company }\end{array}$ & $\mathrm{A} 12$ & 0.509 & 0.011 & 0.011 \\
\hline $\begin{array}{l}\text { The existence of the technical knowledge } \\
\text { and expertise in IT in the company }\end{array}$ & $\mathrm{A} 17$ & 0.496 & 0.011 & 0.011 \\
\hline $\begin{array}{l}\text { The existence of the infrastructures of } \\
\text { telecommunication and broadband } \\
\text { communication }\end{array}$ & $\mathrm{A} 23$ & 0.494 & 0.011 & 0.011 \\
\hline $\begin{array}{l}\text { The knowledge and the awareness of the } \\
\text { senior manager of the company of IT }\end{array}$ & $\mathrm{A} 15$ & 0.487 & 0.011 & 0.01 \\
\hline $\begin{array}{l}\text { The diversity in the tasks performable } \\
\text { through IT }\end{array}$ & $\mathrm{A} 10$ & 0.483 & 0.011 & 0.01 \\
\hline $\begin{array}{l}\text { Increasing the operational efficiency using } \\
\text { IT }\end{array}$ & $\mathrm{A} 7$ & 0.483 & 0.011 & 0.01 \\
\hline The electronic preparation of the & $\mathrm{A} 18$ & 0.481 & 0.011 & 0.01 \\
\hline
\end{tabular}




\begin{tabular}{|l|l|l|l|l|}
\hline organization & & & & \\
\hline $\begin{array}{l}\text { A positive mental impression of the } \\
\text { advantages of using IT }\end{array}$ & $\mathrm{A} 14$ & 0.477 & 0.011 & 0.01 \\
\hline $\begin{array}{l}\text { Increasing the effectiveness of the } \\
\text { organization using IT }\end{array}$ & $\mathrm{A} 8$ & 0.467 & 0.011 & 0.01 \\
\hline $\begin{array}{l}\text { The support of the senior manager of the } \\
\text { company }\end{array}$ & $\mathrm{A} 3$ & 0.466 & 0.011 & 0.01 \\
\hline Creating competitive advantages using IT & $\mathrm{A} 9$ & 0.464 & 0.011 & 0.01 \\
\hline $\begin{array}{l}\text { Conducting the feasibility study of the } \\
\text { application of IT }\end{array}$ & $\mathrm{A} 5$ & 0.462 & 0.011 & 0.009 \\
\hline The suitable price of the required hardware & $\mathrm{A} 20$ & 0.462 & 0.012 & 0.01 \\
\hline Connection to internet & $\mathrm{A} 6$ & 0.456 & 0.011 & 0.01 \\
\hline Support by the government & $\mathrm{A} 19$ & 0.451 & 0.012 & 0.01 \\
\hline $\begin{array}{l}\text { Accessing the IT services outside of the } \\
\text { company }\end{array}$ & $\mathrm{A} 22$ & 0.445 & 0.012 & 0.009 \\
\hline $\begin{array}{l}\text { The existence of the ability of the } \\
\text { management of the change in the company }\end{array}$ & $\mathrm{A} 1$ & 0.443 & 0.012 & 0.01 \\
\hline $\begin{array}{l}\text { The existence of an effective planning in the } \\
\text { company }\end{array}$ & $\mathrm{A} 2$ & 0.432 & 0.012 & 0.009 \\
\hline Training the employees in IT & $\mathrm{A} 4$ & 0.407 & 0.012 & 0.008 \\
\hline
\end{tabular}

Table 8. the general Pearson and Kendall analysis of the correlation between using IT and making Knowledge explicit

\section{Correlations}

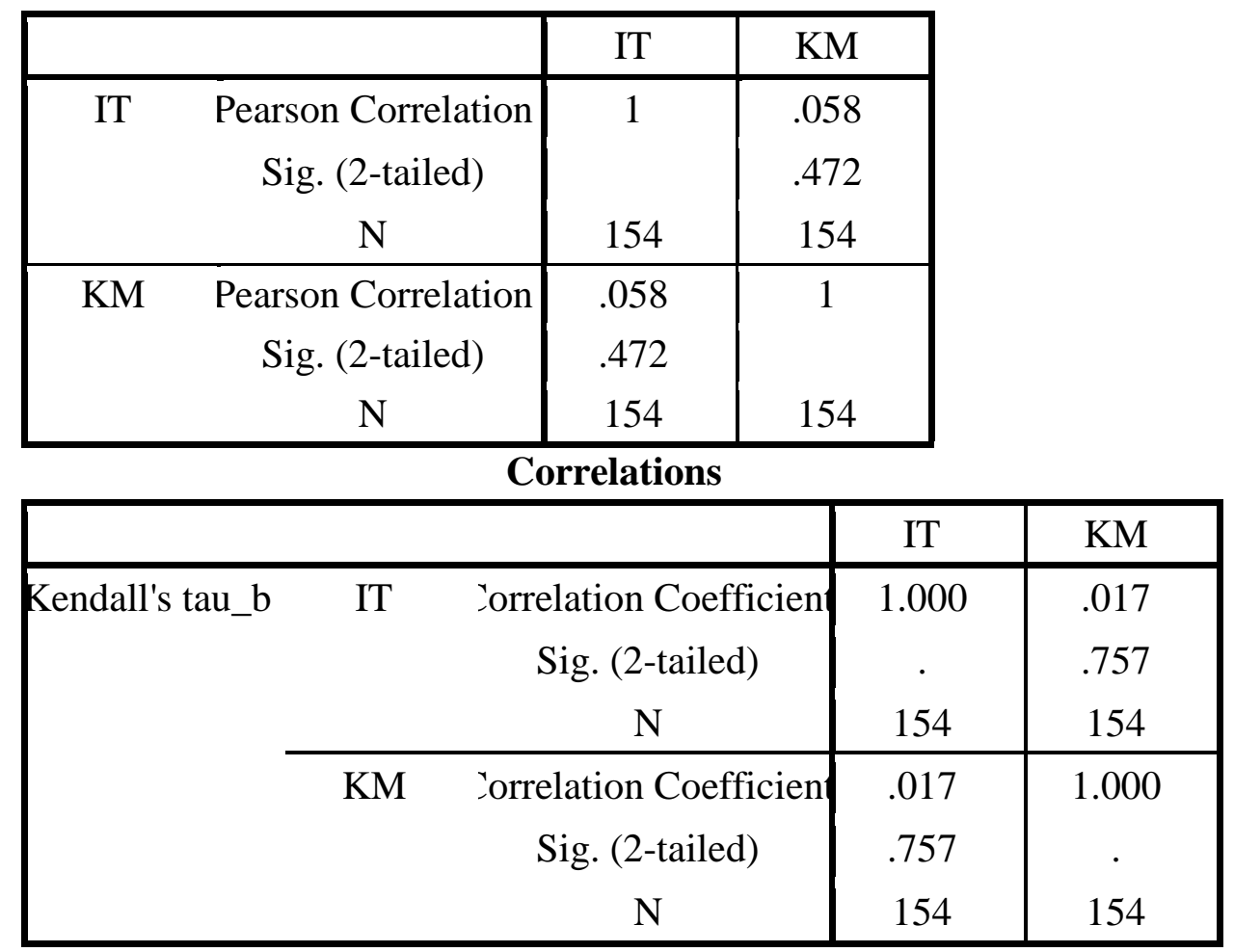

The results of the table above show that although there is a low correlation between the two variables of the research at the level of Pearson correlation 0.058 and the level of Kendall 
correlation 0.017 , this relation is not significant at the levels of error $1 \%$ and $5 \%$. The results of the correlation between other dimensions are as follows.

Table 9.examining the linear relation between the dimensions of using IT and making knowledge explicit

\begin{tabular}{|l|l|l|l|l|l|l|l|l|}
\hline variable & \multicolumn{2}{|l|}{ Process } & \multicolumn{2}{l|}{ Content } & \multicolumn{2}{l|}{ Internal structure } & \multicolumn{2}{l|}{ External structure } \\
\cline { 2 - 8 } & Kendall & Pearson & Kendall & Pearson & Kendall & Pearson & Kendall & Pearson \\
\hline $\begin{array}{l}\text { Making } \\
\text { knowledge } \\
\text { explicit }\end{array}$ & 0.60 & 0.108 & 0.037 & 0.074 & -0.028 & -0.016 & 0.201 & $0.247^{*}$ \\
\hline
\end{tabular}

As the analysis of the correlation between using IT and making knowledge explicit showed, there is a significant relationship only between the dimensions of the external structure and making knowledge explicit at the level of error $1 \%$ and the correlation coefficient 0.247 . This means that factors including support by the government, the suitable price of the required hardware, the suitable price of the required software, accessing the IT services outside of the company and the existence of the infrastructures of telecommunication and broadband communication have the highest effect on making knowledge explicit in the science and technology park in Tehran.

\section{Discussion and Conclusions}

One of the main barriers against making knowledge explicit is sharing inadequate information that can be improved by knowledge sharing strategies. Organizational knowledge can be distributed efficiently through the knowledge sharing process in the organization. When this knowledge is used in other sections of the organization, the organizational performance is improved and promoted. In their article, Khatamianfar\&Parirokh (2007) suggested approaches for sharing the organizational knowledge and one of the most important approaches is creating knowledge communities. Knowledge communities are a network of people interested in a common knowledge field or competition and tending to work together in that field and learn from each other. Also, establishing a database from the best performances and the work experiences, formal meetings, holding problem solving meetings, participating in discussion groups, informal interactions between people, and apprenticeship are other methods in this field.

On the other hand, one of the effective factors discovered in this research that can affect on making knowledge explicit is the positive attitude of the senior manager to the IT and the employees of the companies being examined cited the nonsupport by the manager for renewing IT-based organizational processes as their biggest worry, and its reason is the resistance to change. The following solutions are presented to remove the resources or the factors causing the tendency to constancy.

Considering the facilities: one of the other ways for removing the potential resistances to change is to give something valuable to people while removing their resistance, or to emphasize the benefits from the change. If an IT-based value is demonstrated to the managers, the main part of the problem is undoubtedly solved.

Participation: if the managers participate in making the change and the decision and don't perceive any danger to their organizational position, they rarely resist it. Before making any change, those expected to oppose must be invited and involved in the decision making.

Also, another measure taken important is the integration of IT with the marketing practice of the company that is also referred to as the strategic alignment in the literature. The alignment of 
the IT strategy and the business strategy of the organization is one the main challenges of the current organizations. To achieve this alignment, the IT strategy must note and examine the business limitations in its fields. According to the scientific definitions, alignment is the ability of presenting a definite and practical relation between IT and the financial and the nonfinancial criteria of the performance of an organization. But undoubtedly, the environmental perturbation of the organizations is always a factor for disturbing the balance of these strategies. In one of the comprehensive researches in this field, examining 10 organizational units, Reich\& Benbasat (2000) found that in short term, sharing knowledge among the managers of IT and the managers of the organization and also the history of the successful IT projects in the past lead to a better relation between the managers of IT and those of the organization. And this shared knowledge is taken as the most important factor of the strategic alignment in long term and the strong links between business planning and IT will finally lead to an excellent strategic alignment and the companies of the science and technology park must use this strategy more than ever.

\section{References}

Ahmadi, A., knowledge management in the intellectual organizations, Peikenour Pub., $2^{\text {nd }}$ year, no. 1, 2004.

Afrazeh, A., (explicit and tacit) knowledge management and IT, the first national congress on IT management, 2004.

Afrazeh, A., management of comprehensive information quality in knowledge management, center of informing of the ministry of industry and mines, Iran, 2003.

Jafari, M., Ebnerasoul, S., \& Didehvar, F., the role of knowledge management and IT in the risk management of the project, the international publication of the engineering sciences, no. 5, vol. 17, 2006.

Khatamianfar, P., \& Parirokh, M., the investigation of the circumstances of sharing knowledge in the organization of Ghodserazavi according to Nonaka and Takeuchi model, journal of librarianship and informing, no. 4, vol. 10, ser. 40, pp. 177-212, 2007

Kharghani, S., \& Selseleh, M., typology of the science and technology parks whit the knowledge management approach, the professional journal of parks and the growth centers, no. 20, 2008.

Rafati Shaldehi, H., Hasanavi, R., Behazin, F., \& Banitaba, S.A., the investigation of the pattern of knowledge management in a military research center, journal of military medicine, no. 10, pp. 237-252, 2008.

Salari, N., Poursarajoan, D., Olia, M., \& Shokouhi, Sh., determination and prioritization of the factors effective in the success of knowledge management in the science and technology parks, the professional journal of the parks and the growth centers, no. 27, 2011.

Shahvali, M., \& Lachini, Z., the investigation of the tacit knowledge management of the food security with an emphasis on the organization for the agricultural Jihad, journal of village and development, yr. 10, no. 1, 2007.

Abasi, M., \& Maki, M., the urgency of the innovation in implementing knowledge management and IT management programs in Iran, the professional journal of the parks and the growth centers, no. 24, 2010.

Alidousti, S., factors effective in the development of IT and the electronic commerce in small and big companies, the scientific and research journal of the sciences and IT, pr. 25, no. 3, pp. 529-548, 2010.

Farhoudi, F. \& Doroudi, F., the necessity of using knowledge management in increasing the quality level of the activities of modern organizations, the research center of the information and the scientific documents, Iran, 2008. 
Keramati, M., ZadehGholam, Z., \& Asgari Hosseini, B., the relation of computer training and the efficiency of the scientific heads of the science and technology parks, magazine of technology and training, $2^{\text {nd }}$ yr., vol. 2, no. 3, pp. 205-212, 2008.

Madadi, Y., Manian, A., \& Asgharizadeh, A., the investigation of the role of IT in the effectiveness of the knowledge-based organizations (the case study: college of agriculture and natural resources, Tehran University), magazine of the economy and agricultural development researches, pr. 2, no. 4, Iran, 2010.

Argote, L., McEvily, B., \& Reagans, R., Managing knowledge in organizations: An integrative framework and review of emerging themes, Journal of Management Science, vol.49, no.4, pp 571-582. 2003.

Chinho, L., \& Mei, T., Bridging the implementation gaps in the knowledge management systems for enhancing corporate performance, Journal of Expert Systems with Applications, no.29, pp.163-173, 2005.

Gogan, J.L., The role of imagination in organizing knowledge, European Journal of Information Systems, vol.15, pp. 453-456, 2006.

Huang, H., Shih, H.Y., \& Lin, C.H., Can knowledge management create firm value: Empirical evidence from United States and Taiwan?, Journal of The Business Review, vol.5, no.1, pp.178-183, 2006.

Kane, G.C., \& Alavi, M., Information technology and organizational learning: An investigation of exploration and exploitation processes, Journal of Organization Science, vol.18, no.5, pp.796-812, 2007.

Mohamed, M. \& Stankosky, M., Murray, A., Knowledge management and information technology: can they work in perfect harmony? Journal of Knowledge Management, vol. 10, no.3, pp.103-116, 2006.

Nonaka, I., Takeuchi, H., A Dynamic Theory of Organizational Knowledge Creation, Journal of Organizational Science, vol. 5, no. 1, pp. 14-37, 1994.

Oppong, S.A., A new strategy for harnessing knowledge management in e- commerce, Journal of Technology in Society, vol.27, pp.413-435,2005.

Reich, B.H., \& Benbasat, I.,Factors that influence the social dimension of alignment between business and information technology objectives, MIS Quarterly, vol. 24, Issue.1, pp. 81-113, 2000.

Robertson, J.," Developing knowledge management strategy", Available on: www. jamesr step two.com.au, 2004.

Tseng, Sh.M., The effects of information technology on knowledge management systems, Journal of Expert Systems with Applications, vol. 35. pp. 150-160, 2008.

Vahedi, M., Nejad Haji, A., \& Irani, F., Information technology (IT) for knowledge management, Journal of Procedia Computer Science, vol. 3, pp. 444-448, 2011.

Wen, Y.F., An Effectiveness Measurement Model for Knowledge Management. Knowledge-Based Systems, 2009.

Yang, L.R. and Chen, J.H.; Wang, H.W., Assessing impacts of information technology on project success through knowledge management practice, Journal of Automation in Construction, vol. 22, pp. 182-191, 2012.

Zack, M.H., The strategic advantage of knowledge and learning, International Journal of Intellectual Capital and Learning, vol.2, no.1, pp.1-20, 2005. 